[Aus dem hygienischen Institut in Göttingen.]

\author{
Über die \\ Bedeutung des Bacterium coli für die Wasserbeurteilung. \\ Von \\ Dr. Ernst Quantz, \\ früherem Medizinalpraktikanten am Instlitute.
}

Die Bedeutung des Coligehaltes für die Beurteilung des Trinkwassers ist trotz aller auf die Frage verwandten Mühe auch heute noch nicht geklärt. Wenn sich auch fortwährend die Stimmen derjenigen mehren, die in der Prüfung des Coligehaltes ein wertvolles Mittel der Beurteilung erblicken, und wenn auch im Auslande die Untersuchung auf Coli als ständiges Hilfsmittel der Wasseruntersuchung allgemein eingeführt ist, so steht doch in Deutschland noch eine Reihe von Forschern, und darunter zwei der erfahrensten auf diesem Gebiete, Gärtner und Kruse, der Sache ablehnend gegenüber.

Daß •aber eine Klärung der Frage für die Wissenschaft erwünscht und auch für die praktische Wasserbeurteilung von groBer Bedeutung ist, wird sich kaum betreiten lassen. Denn wenn es auch nie gelingen wird, die Untersuchung des Brunnens durch die Untersuchung des Brunnenwassers vollkommen zu ersetzen, so wäre es doch sicher erwünscht, eine Methode zu besitzen, welche in den nicht seltenen Fällen, in denen die Ortsbesichtigung nicht auszuführen ist, am Wasser das Vorhandensein einer hygienischen Verunreinigung nachzuweisen vermag. Allerdings wird, und das mub von vornherein aufs schärfste betont werden, eine sichere Beurteilung des Brunnens auch im günstigsten Falle nur bei positivem Ausfall der Coliprobe möglich sein; fällt sie negativ aus, so bedarf es einer besonderen Überlegung, wie weit aus dem a ugenblicklichen Fehlen der Verunreinigung auf die dauernde Unmöglichkeit geschlossen werden kann. 
Bei der großen Anzahl der bereits vorliegenden Arbeiten auf diesem Gebiete war es ron cornherein klar, dab eine erneute Bearbeitung der Frage nur dann Berechtigung habe, wenn es gelänge, die Frage von einem neuen oder doch wenigstens ron einem bisher nicht genügend beachteten Gesichtspunkte aus zu untersuchen. Ein solcher scheint mir nun in einer möglichst starken Betonung des quantitativen Coligehaltes und in der möglichst engen Begrenzung des Colibegriffes zu liegen.

Es ist kein Zufall, daB gerade derjenige Autor, der die Verwertung des Colibefundes für die Wasserbeurteilung am schärfsten ablehnt, Weissenfeld, die Grenzen des Colibegriffes am weitesten gezogen und auf die quantitative Seite den geringsten Wert gelegt hat. Weissenfeld ${ }^{1}$ hat alle gramnegativen Bazillen, die morphologisch und in ihrem Wachstum auf Gelatine dem Colibacillus ähnlich sind, zur Coligruppe gerechnet und hat nicht einmal die Milchzuckerzersetzung, die heute wohl allgemein als unerläßliches Kriterium des Colibegriffes angesehen wird, rerlangt. Außerdem hat er sehr grobe Wassermengen, bis zu 2 Liter, durch Anreicherungsverfahren untersucht, und sich so jeder quantitativen Beurteilung begeben. $\mathrm{DaB}$ er auf diese Weise auch in einwandfreien Wässern „Coli" gefunden hat, ist nicht wunderbar.

Auch Konrich ${ }^{2}$, dem wir eine der umfangreichsten und sorgfältigsten Untersuchungen über die Frage rerdanken, und der ebenfalls einen im wesentlichen ablehnenden Standpunkt einnimmt, hat den Colibegriff sehr weit gefaßt. Er begründet das damit, daß die „reaktionsarmen" Coliarten ebenfalls im Darme vorkämen und deshalb auch als Indikatoren angesehen werden müßten.

Eine solche weite Fassung des Colibegriffes hat nun zweifellos den Nachteil, daB dadurch die Gefahr vergröBert wird, Bakterien, die überhaupt nicht aus dem Darme stammen, als Indikatoren zu verwenden. Denn wenn man, wie Konrich und auch andere Autoren es getan haben, nur den Umstand, daB sich das betreffende Bacterium auch im Darm findet, als Kriterium seiner Verwendbarkeit benutzen will, dann braucht man sich schlieBlich auch nicht mehr an die Coligruppe zu halten, sondern kann auch beliebige andere im Darme vorkommende Bakterien für die Beurteilung heranziehen. Die ganze Argumentation Konrichs würde z. B. auch auf den Staphylococcus aureus passen, der auch häufig, fast regelmäBig, in den Fäzes vorkommt, an dessen Verwendung zur Wasserbeurteilung aber doch schwerlich jemand denken wird, weil er in der Außenwelt allzu reichlich vorhanden ist.

1 Weissenfeld, Diese Zeitschrift. Bd. XXXV. S. 78.

${ }^{2}$ Konrich, Klinisches Jahrbuch. 1910. Bd. XXIII. S. 1. 
Wenn das als Indikator benutzte Bacterium seiner Aufgabe gerecht werden soll, so müssen wir eigentlich die GewiBheit haben, daB es selbst wher seine Vorfahren einmal durch den menschlichen oder tierischen Darm hindurchgegangen ist. Diese Gewißheit wird sich allerdings mit unseren jutzigen Methoden schwerlich erreichen lassen. Aber es scheint mir keinem Zweifel zu unterliesen, daB wir diesem Ideal um so näher kommen, und daB die Wahrscheinlichkeit, daB wir es mit einem Darmcoli zu tun haben, um so größer wird, je enger wir den Begriff fassen, und je mehr typische Eigenschaften wir verlangen. Dent wenn auch über die quantitative Beteiligung der typischen und atypischen Coli an der Darmflora noch wenig Angaben vorliegen, so dürfte doch soviel feststehen und allgemein anerkannt sein, da $\boldsymbol{B}$ weitaus am häufigsten die reaktionsreichen, typischen Arten vertreten sind.

Wenn also Fäkalien ins Wasser gelangen, müssen wir erwarten, zunächst diese reaktionsreichen Rassen zu finden und die anderen gar nicht oder doch in geringerer Anzahl anzutreffen. Das ausschlieBliche Auftreten atypischer Arten ist jedenfalls danach nicht $\mathrm{zu}$ erwarten, oder mit anderen Worten, wenn nur solche Arten gefunden werden, so ist anzunehmen, daB sie nicht aus Fäkalien herstammen.

Allerdings müssen, wenn diese SchluBfolgerungen unbedingt gelten sollen, zwei Voraussetzungen erfüllt sein. Es muß erstens vorausgesetzt werden, daB typische und atypische Arten sich gleich gut im Wasser halten, daB jedenfalls die atypischen nicht besser fortkommen, und zweitens, dab keine Umwandlung von typischen in atypische im Wasser stattfindet.

Abschliebende Untersuchungen über diese Fragen liegen noch nicht vor. Die neueren Untersuchungen von Henningson ${ }^{1}$, aus denen der Autor ein besseres Fortkommen der atypischen Sorten im Wasser sehließt, kann ich als vollgültige Beweise nicht anerkennen. Immerhin werden wir die Möglichkeit zugeben müssen, daß tatsächlich eine Begünstigung der atypischen Arten im Wasser stattfindet, wir werden aber weitere Untersuchungen über diese Frage abwarten müssen.

Was den zweiten Punkt anlangt, so ist die Veränderlichkeit der biologischen Eigenschaften des Bacterium coli vielfach behauptet und auch zur Erklärung der atypisehen Formen herangezogen worden. Direkte Versuche unter Bedingungen, die denen in der Natur entsprechen, haben allerdings fast ausnahmslos zu negativen Errgebnissen geführt. Erst ganz kürzlich ist es wieder Henningson gelungen, die Fähigkeit der Gasund Säurebildung durch langen Aufenthalt in Wasser herabzusetzen. Ob

${ }^{1}$ Henningson, Diese Zeitschrift. 1913. Bd. LXXIV. S. 253. 
diese Resultate sich auf die Verhältnisse in Brunnenwasser, in dem eine nennenswerte Vermehrung der Colikeime nicht stattfindet, übertragen lassen, ist mir sehr zweifelhaft; andererseits möchte ich aber doch die Möglichkeit, daB sich in der Natur ein reaktionsreiches typisches Coli in ein atypisches verwandelt, zugeben. Ob das allerdings im Brunnenwasser selbst geschehen kann, und ob nicht zu der Umwandlung so lange Zeiträume nötig sind, dab das Coli dadurch seinen Charakter als Indikator einer gefährlichen frischen Verunreinigung ver]iert, bedarf besonderer Untersuchungen.

Wichtiger noch als die Frage der Begrenzung des Colibegriffes ist die quantitative Bestimmung des Coligehaltes. DaB die einfache Angabe, ob Colibazillen vorhanden sind oder nicht, für die Beurteilung nicht genügt, und daB es deshalb nicht zum Ziele führen kann, wenn man mittels des Anreicherungsverfahrens in einer beliebig groBen Menge Wasser Colibazillen nachweist, wird wohl heute von allen Seiten anerkannt. Alle Untersucher haben sich deshalb mehr oder weniger lebhaft bemüht, quantitatir zu arbeiten. Selbst Weissenfeld ist bis zu einem gewissen Grade quantitativ vorgegangen; er hat seine Wässer in Mengen von $1^{\mathrm{ccm}}$ und von $1 / 2$ bis 1 Liter untersucht, ohne allerdings aus den sich ergebenden Versehiedenheiten Schlußfolgerungen zu ziehen. Und doch zeigen gerade die Weissenfeldschen Untersuchungen auf das klarste, wie nötig and wie wertvoll eine quantitative Betrachtung ist. Denn von seinen ,guten" Wässern zeigten 8 unter 30 (=26.7 Prozent) in einem Kubikzentimeter Coli, die übrigen erst in einem Liter, während bei den schlechten fast immer, und zwar in 24 von 26 (=92.3 Prozent) schon in $1^{\mathrm{cem}}$ Coli gefunden wurde.

Der Grund für die Notwendigkeit des quantitativen Vorgehens liegt in der großen Verbreitung der Colibakterien und der dadurch bedingten Gefahr, daB sie auf Wegen ins Wasser gelangen, auf denen Fäkalien oder sonstige infektionsverdächtige Dinge nicht hineingelangen können.

Zweifellos können die Hände der die Wasserproben entnehmenden Person durch Berührung der Gefäbwände oder des AusfluBrohres beim Pumpen Coli übertragen, durch den Luftstaub können Keime hineingelangen, und hineinfallende Gegenstände, Blätter, Erdpartikelchen, können ebenfalls Coli hineinbefördern. Die Ubiquität des Bacterium coli ist trotz des Mißbrauches, der vielfach mit dem Worte getrieben wurde, insofern gewiß anzuerkennen, als außerordentlich leicht auf diesen oder ähnlichen Wegen Colikeime nachträglich in Wasserproben gelangen lönnen. Selbstverständlich müssen aber solche zufälligen Verunreinigungen durch Coli von der Indikatorrolle ausgeschlossen werden; denn der Wert 
des Coli als Indikator kann, wenn er überhaupt vorhanden ist, nur auf der Überlegung beruhen, daB auf demselben Wege, auf dem das Coli hineingekommen ist, auch pathogene Bakterien, insbesondere Typhusbazillen, hineingelangen können. Das ist aber bei Verunreinigungen der genannten Art ausgeschlossen, oder doch mindestens sehr unwahrscheinlich.

Es unterliegt nun keinem Zweifel, daß diese zufälligen Verunreinigungen durch Coli meistens quantitativ nur unbedeutend sein werden, und das ist der Grund, weshalb auf die Zahl der Colikeime so groBer Wert gelegt werden muB. Natürlich wird sich darin gebe ich Konrich durchaus recht - ein Grenzwert nicht von vornherein aufstellen lassen. Man kann nicht ohne weiteres sagen, welche Colizahl überschritten werden muß, damit auf eine verdächtige Verunreinigung geschlossen werden darf.

Fassen wir nun die bisherigen Utberlegungen zusammen, so kommen wir zu dem Schlub, daB sich weder über die Art noch über die Zahl der Colikeime in guten und schlechten Wässern sichere Voraussagen treffen lassen. Wir können wohl mit einer gewissen Wahrscheinlichkeit annehmen, daB eine frische Fäkalverunreinigung in einer reichlichen Anzahl typischer Colibakterien zum Ausdruck kommt, und daß das Vorhandensein weniger oder ausschlieBlich atypischer Keime das Wasser nicht verdächtig zu machen braucht. Sicheres darüber läBt sich aber a priori nicht sagen - auf deduktivem Wege wird sich also die Colifrage überhaupt nicht lösen lassen. Wenn wir vorwärts kommen wollen, müssen wir induktiv vorgehen: wir müssen empirisch feststellen, welche Art und welche Zahl von Colikeimen sich in Wasser findet, die wir nach anderen Beurteilungsmethoden, insbesondere nach der Ortsbesichtigung als einwandsfrei oder nicht einwandsfrei erkannt haben. Nur durch solche Untersuchungen, die in möglichst grober Zahl angestellt werden müssen, ist meines Erachtens die Frage zu lösen.

Ich habe deshalb auf Anregung von Hrn. Prof. Reichenbach mir die Aufgabe gestellt, bei einer möglichst großen Anzahl von Wassergewinnungsanlagen, insbesondere von Brunnen, das Resultat des Colinachweises mit dem Ergebnis der Besichtigung zu vergleichen. Auch die gewöhnliche Keimzählung sollte zum Vergleich mit herangezogen werden, und ebenso die chemische Untersuchung, die letztere weniger in der Absicht der Kontrolle, als in der sicheren Voraussetzung, daB sich ihr geringer Wert auch bei diesen Untersuchungen herausstellen würde. 


\section{Methode der Untersuchungen.}

Der Colinachweis ist bisher fast allgemein durch das Anreicherungsverfahren geführt worden, und zwar quantitativ nach dem Vorgang von Petruschky und Pusch durch Feststellung des Colititers, d. h. der geringsten Wassermenge, in der sich noch Coli nachweisen läßt. Es ist aber allgemein anerkannt, daß dies Verfahren, abgesehen von seiner Umständlichkeit, verschiedene Unzuträglichkeiten besitzt. Zunächst ist die Frage, welche Nährlösung für die Anreicherung am günstigsten ist, und bei welcher Temperatur sie gehalten werden soll, noch nicht entschieden. Konrich, der die sehr zahlreichen in der Literatur angegebenen Verfahren übersichtlich zusammengestellt hat, hat eigene Untersuchungen mit zwei Methoden, und zwar mit der von Mac Conkey und von Eijkman angestellt. Dabei haben sich sehr große Unterschiede im Titer gefunden, je nachdem er die eine oder die andere Lösung verwandte. Von 100 Proben gaben nur 36 übereinstimmende Resultate, im allgemeinen gab Mac Conkey höhere Titer als Eijkman. Noch bedenklicher ist, daB häufig durch die beiden Verfahren in derselben Wasserprobe vollständig verschiedene Coliarten gefunden werden, und daß ferner, ebenfalls in derselben Probe, die kleine Wassermenge ein positives, die grobe Wassermenge ein negatives Resultat lieferte. Auch ein vollständiges Versagen der Anreicherung in sicher colihaltigem Wasser kommt nicht selten vor. So hat z. B. Fromme ${ }^{1}$ im Elbwasser auch bei Untersuchungen grober Mengen nur in 79.2 Prozent der Proben Coli nachweisen bönnen, obwohl das Vorhandensein in allen wohl als sicher angenommen werden lann. Man liann sich, wenn mal. sich die ganzen Resultate der zahlreichen Anreicherungsversuche vergegenwärtigt, des Eindruckes nicht erwehren, daß für den Ausfall der Probe nicht nur der Coligehalt, sondern auch andere Umstände, wahrscheinlich der Gehait an anderen Bakterien, vielleicht auch die Zusammensetzung des Wassers, maBgebend ist, und daB deshalb ein sicherer Aufschlub über das Vorkommen von Coli weder in quantitativer noch in qualitativer Hinsicht damit zu erzielen ist.

Es lag nun für mich nahe, das im hiesigen Institut durch v. Esmarch angegebene und von Marmann ${ }^{2}$ ausgearbeitete und beschriebene Verfahren des quantitativen Colinachweises zu versuchen. Das Verfahren berubt darauf, daB das zu untersuchende Wasser auf eine Drigalskioder Endoplatte gegossen wird und durch mäBig warmen Luftstrom zur Verdunstung gebracht wird. Man kann auf diese Weise verhältnismäBig große Mengen ( 5 bis $10^{\mathrm{cm}}$ ) untersuchen und hat den großen Vorteil,

1 Fromme, Diese Zeitschrift. 1910. Bd. LXIII. S. 251.

2 Marmann, Centralblatt f. Bakteriologie. .1909. Orig. Bd. I. S. 267. 
daB man von den vorhandenen Colikeimen direkt Kolonien erhält, deren Zahl und Art sich leicht feststellen läBt.

Das Verfahren ist von Oettinger ${ }^{1}$ für die Prüfung von Sandfiltern angewandt und hat sich dafür ebenfalls gut bewährt.

Ein Nachteil des Verfahrens wird von vielen Seiten darin erblickt werden, daß es gegenüber dem Anreicherungsverfahren nur relativ kleine Wassermengen zu untersuchen gestattet. Über 10 bis höchstens $20 \mathrm{ccm}$ kann man nicht gut auf der Platte zur Verdunstung bringen. Man kann zwar durch Verwendung mehrerer Platten die Wassermenge beliebig steigern, doch wird dann das Verfahren kostspielig und umständlich.

Dieser Nachteil, der für manche Untersuchungen zugegeben werden muß, fällt für unsere Fragestellung nicht ins Gewicht, denn uns kommt es ja gar nicht darauf an, zu prüfen, in wieviel Wasser bei Verwendung sehr großer Wassermengen Coli. sich nachweisen läbt, sondern es soll untersucht werden, wie sich quantitativ in guten und schlechten Wässern das Coli verhält. Für diesen Zweck konnte ich auf die Verwendung großer Wassermengen verzichten, im Gegenteil, es war von vornherein nicht unwahrscheinlich, dab der Unterschied, der gerade durch die Verwendung sehr grober Mengen verwischt wird, bei Untersuchung kleiner Mengen sehr deutlich hervortreten würde.

Ein anderes Bedenken gegen die Methode könnte darin liegen, daB manche lebensschwächere Keime, die beim Anreicherungsverfahren in dem flüssigen Nährboden gut zur Vermehrung kommen, unter den ungünstigeren Bedingungen des festen Nährbodens nicht mehr auswachsen, und daB dadurch die Methode eine weitere EinbuBe an Empindlichkeit erlitte. Aber auch dieses Bedenken, das theoretisch gewiB nicht unberechtigt ist, läBt sich in diesem speziellen Falle mit der Überlegung abweisen, daB die erhaltenen Resultate selbstverständlich nur für die benutzte Methode gültig sein können, und daß bei der praktischen Benutzung des Beurteilungsverfahrens genau nach derselben Methode vorgegangen werden muB, wie sie bei der Erprobung verwandt wurde. $\mathrm{Ob}$ die Methode dann etwas mehr oder weniger empfindlich ist, ist gleichgültig.

Vergleichende Untersuchungen mit der Anreicherung, und zwar nach Petruschky und Pusch und Eijkman und dem Göttinger Verfahren sind von Marmann mitgeteilt worden. In manchen Fällen erwies sich das Anreicherungsverfahren etwas empfindlicher, es kam aber auch vor, dab nach dem Plattenrerfahren noch Coli nachgewiesen wurde, wenn das Anreicherungsverfahren versagte. Nicht selten lieferte das Anreicherungsverfahren paradoxe Resultate insofern, als es in großen Mengen negativ und in kleinen Mengen positiv ausfiel.

${ }^{2}$ Oettinger, Diese Zeitschrift. 1912. Bd. LXXI. S. 1. 
Obwohl eine eingehende Vergleichung der beiden Verfahren nicht im Plane meiner Arbeit lag, schien es mir doch von Interesse an einer kleinen Reihe von Wässern Paralleluntersuchungen anzustellen, um mir so ein eigenes Urteil bilden zu können. Es wurden untersucht: 2 Quellen, 13 Kesselbrunnen und 8 Rammbrunnen, und zwar wurden mit dem Göttinger Verfahren 15 bis $20^{\mathrm{cm}}$ auf zwei bis drei Platten, mit der Anreicherung 5 bis $150^{\mathrm{cm}}$ untersucht. Als Anreicherungsflüssigkeit wurde 1 prozentige Peptonbouillon mit 1 Prozent Traubenzucker benutzt.

Von den Quellen war die eine mit beiden Verfahren colifrei, die andere gab auf der Platte vier Keime und im flüssigen Nährboden Coli bei Verwendung von $50 \mathrm{~cm}$. Die Kesselbrunnen gaben sämtlich mit beiden Verfahren Coli, von den Rammbrunnen erwiesen sich vier mit beiden Verfahren als colifrei, einer, der in $20^{\mathrm{cm}}$ auf der Platte vier Coli enthielt, gab bei der Anreicherung in $100 \mathrm{cem}$ kein Coli; ein anderer verhielt sich umgekehrt: auf der Platte war kein Coli nachzuweisen, während bei der Anreicherung von $50^{\mathrm{cem}}$ ab reichlich Coli vorhanden war. Erhebliche Unterschiede in der Empfindlichkeit waren also hierbei nicht festzustellen.

Etwas größer waren die Abweichungen bei einer zweiten Versuchsreihe, die am Göttinger Leitungswasser angestellt wurde. Nach Ingebrauchnahme eines neuen Reservoirs wurden täglich Proben aus dem Druckrohr und dem Fallrohr untersucht, und zwar im ganzen 48 Proben. Von jeder Probe wurden drei Platten, zwei Endo- mit 10 und $5^{\mathrm{ccm}}$ und eine Drigalskiplatte mit $10^{\mathrm{cm}}$ angelegt, für die Anreicherung wurden 1 bis $200^{\mathrm{cem}}$, manchmal auch $500^{\mathrm{em}}$ benutzt.

Colifrei nach beiden Methoden waren 11 Proben, colihaltig 18. Bei 7 Proben zeigte sich das Göttinger Verfahren überlegen; hier waren in der untersuchten Wassermenge Coli nachzuweisen, während das Anreicherungsverfahren auch in Mengen von 250 bis 500 cem versagte. Umgekehrt lieferte in 9 Fällen das Anreicherungsverfahren den Nachweis von Coli, während mit dem Göttinger Verfahren keine gefunden wurden. Allerdings waren hierzu immer größere Quantitäten erforderlich.

Eine Oberlegenheit des Anreicherungsverfahrens ist also auch hiernach, wenn überhaupt, nur insofern vorhanden, als damit gröBere Wassermengen untersucht werden können, eine Erleichterung des Wachstums einzelner Colikeime durch den flüssigen Nährboden findet nicht statt. Im Gegenteil, es scheint als ob einzelne Keime nicht selten auf der Platte noch sichtbar werden, wenn sie im flüssigen Nährboden der Konkurrenz der Begleitbakterien erliegen. Von der Menge und der Art der Begleitbakterien scheint überhaupt der Erfolg des Anreicherungsverfahrens sehr abhängig zu sein. 
Einen besonders großen Vorteil des Plattenverfahrens erblicke ich darin, daB es mit seiner Hilfe gelingt, alle im Wasser vorhandenen Coliarten zur Anschauung zu bringen und auch ihre quantitative Beteiligung an der Wasserflora festzustellen, während das Anreicherungsverfahren meistens nur diejenige Art zur Entwicklung kommen läBt, die gerade, vielleicht zufällig, die besten Wachstumsbedingungen findet. Ich halte es nicht für unmöglich, da $B$ der auffällige, unter anderen auch von Konrich erhobene Befund, nach dem in einem sicher fäkal verunreinigten Wasser nur atypische Coli gefunden wurden, auf einer Uberwucherung der typischen Arten beruht. Bei Anwendung des Plattenverfahrens würde sich vielleicht ein anderes Resultai ergeben haben. Meine eigenen später noch zu besprechenden Resultate, bei denen kaum jemals $\mathrm{n} u \mathrm{r}$ atypisches Coli gefunden wurde, unterstützen diese Vermutung.

\section{Definition des Colibegriffes.}

Was ist nun unter typischem und atypischem Coli zu verstehen? Welche Eigenschaften sind unerläBlich für ein typisches Coli? Folgende Eigenschaften müssen meines Erachtens für den Begriff des Coli unbedingt verlangt werden:

1. Morphologie. Mehr oder weniger schlanke, bis ziemlich plumpe Stäbchen.

2. Beweglichkeit. Beweglich.

3. Verhalten auf Gelatine. Bildet auf der Oberfläche durchscheinende, unregelmäßig konturierte, nicht verflüssigende Kolonien.

4. Verhalten zur Gramfarbe. Negativ.

5. Verhalten zu Traubenzucker. Bildet Gas und Säure.

6. Verhalten zu Milchzucker. Bildet innerhalb 24 Stunden reichlich Säure, koaguliert deshalb auch Milch und bildet auf Drigalskiagar deutlich rote Kolonien.

7. Verhalten zu Neutralrot. Starke deutliche Reduktion unter Gelbfärbung und Fluoreszenz in spätestens 48 Stunden.

8. Verhalten auf Endoagar. Tiefrote Kolonien mit metallischem Fuchsinglanz und rotem Hof.

Das sind die Eigenschaften, die wir bei der weitaus überwiegenden Mehrzahl der Darmcoli finden, und die deshalb aus den vorhin auseinandergesetzten Gründen als Bedingung für die Diagnose Coli angesehen werden müssen. Bei anderen Eigenschaften kann man zweifelhaft sein, ob man sie als unerläBlich ansehen soll; hier könnte nur eine genaue statistische 
Untersuchung entscheiden, ein wie großer Prozentsatz der Coli sie besitzt. Dahin gehören z. B. die Indolbildung und die Zersetzung von Saccharose. Diese habe ich vorläufig nicht in die Begriffsbestimmung aufgenommen; ich halte es aber sehr wohl für möglich, daß genauere Untersuchungen dahin führen werden, auch sie als Eigensehaft des typischen Coli aufzufassen.

Eine Eigenschaft, die vielleicht in Zukunft für die Beurteilung der Rassenzugehörigkeit der Colibakterien Bedeutung gewinnen wird, ist die quantitative Säurebildung. Ich bin von Prof. Reichenbach darauf aufmerksam gemacht worden, da $\boldsymbol{B}$ bei der überwiegenden Mehrzahl der Coli unter bestimmten Bedingungen eine ganz bestimmte Säuremenge gefunden wird.

Da die Menge der durch eine bestimmte Bakterienart gebildeten Säure nicht nur von der Art des vorhandenen Zuckers, sondern in noch höherem MaBe von der Zusammensetzung der Nährlösung abhängig ist, muB natürlich, um vergleichbare Werte zu erhalten, immer dieselbe Nährlösung benutzt werden. Die häufig angewandte Bouillon ist für quantitative Untersuchungen wegen ihrer schwankenden Zusammensetzung ungeeignet. Der von Prof. Reichenbach benutate Nährboden hat folgende Zusammensetzung:

\begin{tabular}{|c|c|c|c|c|c|c|c|c|}
\hline \multirow{2}{*}{\multicolumn{2}{|c|}{$\begin{array}{l}\text { Wasser . } \cdot \dot{\cdot} \\
\text { Dinatriumphosphat }\end{array}$}} & & & & & & & $1000 \cdot 0$ \\
\hline & & & & . & & & & $2 \cdot 5$ \\
\hline Asparagin . & . . & . & & . & & & & $4 \cdot 0$ \\
\hline Kochsalz & . & . & . & . & & & & $5 \cdot 0$ \\
\hline Pepton Witte & & & & . & . & & & $2 \cdot 5$ \\
\hline Milchzucker & . & . & . & . & & & & $5 \cdot 0$ \\
\hline Azolitmin . & & & & & & & & 0.25 \\
\hline
\end{tabular}

Die fertige Lösung reagiert neutral, Bact. coli wächst darin sehr üppig und erreicht das Maximum der Säurebildung am 4. Tage. Da der erreichte Säuregrad bis zu einem gewissen Grade von der Weite des Röhrchens abhängig ist, ist es zweckmäßig, immer gleichweite Röhrchen zur Titration zu benutzen. Als Flüssigkeitsmenge wird am zweckmäBigsten $10^{\mathrm{ccm}}$ benutzt. Die Titration wurde mit $1 / 10$ Normallauge ausgeführt; als Endpunkt wird der Farbenton der unbeimpften Lösung angesehen. Die Vergleichung läßt sich am besten vornehmen, wenn man das Röhrchen in schräger Lage über einen weißen Untergrund hält.

Die meisten aus dem Darm frisch isolierten Coliarten geben auf diese Weise eine Säurebildung von 2.5 bis $2.7 \mathrm{~cm} 1 / 10$ Normallauge auf $10^{\mathrm{cm}}$ Nährflüssigkeit. Bei einer Reihe der aus dem Wasser isolierten Coli- 
stämme habe ich diese Bestimmung der quantitativen Säurebildung ausgeführt, über die Resultate werde ich später berichten.

Einer besonderen Überlegung bedurfte schlieBlich doch die Frage, bei welcher Temperatur die Coliplatten bebrütet werden sollten. Eijkman hat bekanntlich die Eigenschaft des typischen Warmblütercolis, bei $46^{\circ}$ zu wachsen, benutzt, um sie von Kaltblütercolis zu unterscheiden. Nun kann es wohl keinem Zweifel unterliegen, daß ein Colibacterium, das bei $46^{0}$ wächst, nicht aus dem Kaltblüterdarm stammt. Aber andererseits ist von zahlreichen Autoren darauf hingewiesen worden, dab keineswegs alle, im übrigen typischen Warmblütercolis bei $46^{\circ}$ gedeihen. Marmann und auch Schürer ${ }^{1}$, die mit dem Göttinger Verfahren gearbeitet haben, haben ihre Kulturen bei $41^{\circ}$ gehalten, weil sie dadurch eine groBe Zahl der Begleitbakterien ausschließen konnten, während das Bacterium coli bei $41^{\circ}$ noch nicht geschädigt wurde. Parallelversuche aber, die ich selbst bei 41 und $37^{\circ}$ angestellt habe, führten $\mathrm{zu}$ dem Resultat, daB doch auch schon bei $41^{\circ}$ eine, wenn auch nur geringe, Behinderung des Coliwachstums stattfindet. Ich habe mich bei der Untersuchung von Brunnenwässern nicht von dem Vorteil der Anwendung von $41^{\circ}$ überzeugen können, und habe infolgedessen fast ausschlieblich $37^{\circ}$ zur Bebrütung verwandt. $O b$ bei dieser Temperatur noch Kaltblütercoli gedeihen, bedarf allerdings besonderer Untersuchungen. Die Frage kommt aber fur die Untersuchung von Brunnen, mit denen ich mich fast ausschlieBlich beschäftigt babe, weniger in Betracht als für offene Wasserläufe.

\section{Eigene Untersuchungen ron Wasserproben.}

Nach den oben geschilderten Prinzipien habe ich nun eine ganze Reihe von Wasserproben auf Coli untersucht und gleichzeitig durch die Ortsbesichtigung ein Urteil über die hygienische Wertigkeit der Wasserbezugsstelle mir zu bilden versucht. AuBer der Coliprobe wurde auch noch die gewöhnliche Keimzählung und die chemische Untersuchung vorgenommen. Die Wasserproben wurden durchweg von mir selbst entnommen, so rasch wie möglich ins Laboratorium gebracht und sofort auf Platten ausgesät. Es wurden meist zwei Platten mit gewöhnlicher Gelatine, zwei Endoplatten mit 5 und $10 \mathrm{~cm}$ und eine Drigalskiplatte mit $5 \mathrm{~cm}$ angelegt, so daB also $20 \mathrm{~cm}$ zum Colinachweis benutzt wurden.

Chemisch wurde Chlor quantitativ, Salpetersäure, salpetrige Säure, Ammoniak und Phosphorsäure qualitativ bestimmt.

${ }^{1}$ Schürer, Über den Nachweis des Bacterium coli im FluBwasser. InauguralLissertation. Göttingen 1910. 
Die Prüfung der Platten geschah nach 24 und 48 Stunden. Ein groBer Teil der Colikolonien zeigt schon nach 24 Stunden deutlichen Fuchsinglanz, es kommt aber auch doch nicht selten vor, besonders wenn der Nährboden reichlich Natriumsulfit enthält, daB die Kolonien erst am 2. Tage ganz typisches Aussehen zeigen. Unseren Anschauungen gemäB wurden nur die Kolonien mit deutlichem Fuchsinglanz gezählt. Ich habe mich durch häufige Nachprüfungen davon überzeugt, daß Kolonien, die nur Rötung zeigen, entweder den Milchzucker überhaupt nicht zersetzen oder doch in anderen Eigenschaften stark vom typischen Coli abweichen. Von den fuchsinglänzenden Kolonien wurde eine Anzahl näher auf die für das typische Coli geforderten Eigenschaften untersucht, bei vielen auch die quantitative Säurebildung bestimmt.

Um den Vergleich der an den Wasserproben gewonnenen Untersuchungsresultate mit der hygienischen Beschaffenheit der Brunnen gut durchführen zu können, wird es zweckmäbig sein, die verschiedenen Brunnenkonstruktionen besonders $z u$ betrachten. Unter Kessel- oder Schachtbrunnen sollen alle diejenigen Konstruktionen verstanden werden, bei denen das Saugrohr der Pumpe sich in einem mehr oder weniger weiten Schachte befindet, bei dem also auBer im Saugrohr noch ein Wasservorrat vorhanden ist. Dabei ist die Weite des Schachtes gleichgültig; es sind also hierher auch diejenigen in einigen Fällen angetroffenen Brunnen $\mathrm{zu}$ rechnen, bei denen das Saugrohr in einem besonderen aus Eisen oder Ton hergestellten Rohre heruntergeführt ist.

Rammbrunnen nenne ich diejenigen Brunnen, bei denen das mit einer Spitze versehene Saugrohr (sogenanntes Abessinierrohr) direkt in den Boden getrieben ist.

\section{Kesselbrunnen.}

Nach dem Vorgange von Reichenbach ${ }^{1}$ habe ich die Kesselbrunnen nach ihrer hygienischen Beschaffenheit in drei Gruppen eingeteilt. Gruppe I umfaBt die in jeder Beziehung einwandfreien Brunnen. Der Schacht war aus dichtgefügtem Maverwerk oder aus Zementröhren hergestellt und vollkommen wasserdicht nach oben abgeschlossen; das Saugrohr befand sich meist seitlich vom Schacht oder war absolut dicht durch die obere Abdeckung hindurchgeführt. Das gepumpte Wasser konnte nicht in den Brunnen zurücklaufen. Auch die Umgebung dieser Brunnen war so, daß ein Verdacht auf eine unterirdische Verunreinigung nicht erweckt werden konnte. Kurz gesagt, die Brunnen

1 Reichenbach, Hyg. Rundschau. 1903. Bd. XIII. S. 433. 
der Gruppe I waren, soweit sich das überhaupt durch Ortsbesichtigung feststellen läBt, gegen Verunreinigung vollkommen geschützt.

Zur zweiten Gruppe wurden die Brunnen gerechnet, bei denen die Möglichkeit der Verunreinigung nicht ganz ausgeschlossen werden konnte, bei denen aber weder der Zustand der Brunnen, noch ihre Jmgebung so waren, dab eine zurzeit vorhandene Verunreinigung allein aus der Ortsbesichtigung als sicher angenommèn werden muBte. Jeder, der die Brunnenverhältnisse kennt, weib, dab zu dieser Kategorie die meisten der vorhandenen Brunnen gehören.

Von dieser zweiten Gruppe ist die dritte nur quantitatip verschieden. $\mathrm{Zu}$ ihr habe ich diejenigen Brunnen gerechnet, bei denen wegen des mangelhaften Zustandes des Schachtmauerwerkes oder der Abdeckung oder nach der Terraingestaltung oder nach der Anordnung des Abflusses angenommen werden mußte, daB verunreinigende Zuflüsse von der Erdoberfläche oder aus den oberen Bodenschichten ständig oder doch wenigstens sehr häufig in sie hinein gelangen. Eine scharfe Grenze gegenüber der Gruppe II existiert aber nicht; bei der Abgrenzung der beiden Gruppen hat sich also eine gewisse Willkür nicht vermeiden lassen.

Von den 155 untersuchten Kesselbrunnen gehörten 23 zur Gruppe I, 97 zur Gruppe II und 35 zur Gruppe III.

Eine Anzahl von ihnen wurden im Abstand von einigen Monaten zum zweiten Male, einige auch zum dritten Male untersucht.

Die nähere Betrachtung der Untersuchungsresultate werden wir am zweckmäßigsten nach diesen Gruppen getrennt vornehmen.

Sehen wir zunächst den chemischen Befund an.

Der Chlorgehalt der ersten Gruppe schwankte zwischen 7 und $250^{\mathrm{mg}}$ und betrug im Mittel $46 \cdot 6^{\mathrm{mg}}$.

Von den 97 Brunnen der zweiten Gruppe wurden 23 zweimal untersucht.

Das Mittel aus sämtlichen Untersuchungen ergab $48 \cdot 6^{\mathrm{mg}}$ Chlor, das Maximum betrug $266^{\mathrm{mg}}$, das Minimum $8^{\mathrm{mg}}$. Ein Brunnen mit einem Chlorgehalt von über $1000^{\mathrm{mg}}$ wurde dabei auBer acht gelassen, weil er in der Nähe einer Saline stand; sein hoher Chlorgehalt entstammt also wohl dem natürlichen Mineralgehalt des Bodens und kann deshalb nicht als Indikator der Verunreinigung betrachtet werden.

Die Gruppe III ergab als Mittel aus sämtlichen Untersuchungen

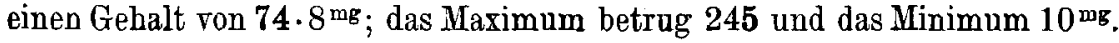

Steht nun der Chlorgehalt in irgendwelcher Beziehung zu der hygienischen Wertigkeit der Brunnen, und läBt sich aus dem Chlorgehalt ein SchluB auf die Beschaffenheit der Brunnen ziehen? 
Tabelle I.

\begin{tabular}{r||c|c|c}
\hline \multirow{2}{*}{ Gruppe } & \multicolumn{3}{|c}{ Milligramm Cl im Liter } \\
& Maximum & Minimum & Mittel \\
\hline I & 263 & 7 & $46 \cdot 6$ \\
II & 266 & 8 & $48 \cdot 6$ \\
III & 245 & 10 & $74 \cdot 8$
\end{tabular}

Betrachten wir zunächst die Maxima und Minima, so sehen wir, daB Kaum Unterschiede zwischen den drei Gruppen der Brunnen bestehen, d. h. es kommen gute Brunnen mit groBem und schlechte Brunnen mit geringem Chlorgehalt vor. Auch die Mittelzahlen verhalten sich nicht viel anders: zwischen Gruppe I und II ist kaum ein Unterschied vorhanden, während allerdings die dritte Gruppe eine erhebliche Errhöhung des mittleren Chlorgehaltes aufweist.

Etwas günstiger scheint das Bild zu werden, wenn wir untersuchen, mit welcher Anzahl von Brunnen die einzelnen Gruppen an den verschiedenen Chlorgehaltsstufen beteiligt sind (s. Tabelle II). Hier sehen wir tatsächlich, daß der niedrige Chlorgehalt bei den Brunnen der ersten Gruppe überwiegt, und daB Gruppe II und III relativ mehr Brunnen mit hohem Chlorgehalt besitzen. Wollten wir den früher wohl als Grenzwert angesehenen Gehalt von $30 \mathrm{mg}$ heute noch als gültig betrachten, so würden unter diesem Werte bleiben von Gruppe I 71 Prozent, von Gruppe II 37 Prozent, von Gruppe III 29 Prozent. Eine gewisse Beziehung zwischen Chlorgehalt und hygieniseher Beschaffenheit der Brunnen ist also nicht zu verkennen. Trotzdem geht aber auch aus diesen Zahlen hervor, dab für die Beurteilung des einzelnen Falles der Chlorgehalt als Kriterium durchaus wertlos ist. Was kann eine Beurteilungsmethode nützen, wenn sie fast bei einem Drittel der Fälle versagt?

Tabelle II.

\begin{tabular}{c|c|c|c|c|c|c|c}
\hline \multirow{2}{*}{$\begin{array}{c}\text { Chlorgehalt } \\
\text { (mg im Liter) }\end{array}$} & \multicolumn{3}{|c|}{ Zahl der Brunnen } & \multicolumn{3}{|c|}{ Prozent der untersuchten Brunneu } \\
\cline { 2 - 7 } & Gruppe I & Gruppe II & Gruppe III & \multicolumn{2}{|c|}{ Grappe I } & Gruppe II & Gruppe III \\
\hline \hline $0-10$ & 4 & 3 & 1 & 19 & 4 & 3 \\
$11-20$ & 7 & 13 & 3 & 33 & 16 & 9 \\
$21-30$ & 4 & 14 & 6 & 19 & 17 & 17 \\
$31-50$ & 0 & 21 & 8 & 0 & 26 & 23 \\
$51-100$ & 3 & 19 & 7 & 14 & 23 & 20 \\
$101-200$ & 2 & 11 & 7 & 10 & 13 & 20 \\
Über 200 & 1 & 1 & 3 & 5 & 1 & 8 \\
Nicht & 2 & 15 & 0 & & & \\
untersucht & & & & & &
\end{tabular}


29 Prozent der untersuchten notorisch guten Brunnen haben den Grenzwert überschritten, während ebenso gerade 29 Prozent der notorisch schlechten unter dem Grenzwert bleiben. Und wenn wir statt der $30^{\mathrm{mg}}$ einen anderen Grenzwert einsetzen, so wird dadurch das Urteil nicht geändert; bei $20^{\mathrm{mg}}$ würden z. B. 48 Prozent der guten Brunnen als schlecht und 12 Prozent der sicher guten als schlecht befunden werden.

Ich möchte aber noch weiter gehen. Auch der geringe hier gefundene Grad der Übereinstimmung zwischen Chlorgehalt und Beschaffenheit der Brunnen braucht nicht allgemein zuzutreffen, sondern ist höchstwahrscheinlich nur durch die besonderen Verhältnisse dieser Untersuchung bedingt. Die einwandfreien Brunnen waren meistens noch nicht sehr alt, und lagen häufig auf einem erst kurze Zeit bebauten Terrain. Die schlechtesten Brunnen dagegen lagen in den ältesten Stadtteilen oder in ländlichen Anwesen in engen Höfen und gröBtenteils auf einem Boden, der seit längerer Zeit der Durchtränkung mit Abfallstoffen ausgesetzt war. Das mußte natürlich bis zu einem gewissem Grade im Chlorgehalte des Wassers zum Ausdruck kommen. Der Chlorgehalt des Brunnens ist deshalb auch, wie das schon von Reichenbach hervorgehoben worden ist, mehr rom Bebauungsalter des Terrains, auf dem er liegt, als von seiner Beschaffenheit abhängig. Eine hygienische Bedeutung ist aber diesen Verunreinigungen, die vor vielen Jahrzehnten erfolgt sein können und den Keimgehalt des Wassers absolut nicht zu beeinflussen, geschweige denn pathogene Keime hineinzubringen brauchen, sicher nicht zuzuerkennen.

Nicht anders liegt die Sache mit den übrigen chemischen Bestandteilen, die früher gewöhnlich als Ausdrack von bedenklichen Verunreinigungen angesehen wurden. Ammoniak wurde verhältnismäBig selten gefunden, in der Gruppe I einmal, d. h. in 4 Prozent der Fälle, in der Gruppe II $7 \mathrm{mal}$ und in der Gruppe III $5 \mathrm{mal}$, also in 14 Prozent. Auffallend häufig wurde salpetrige Säure, meistens allerdings nur in ganz geringen Spuren, gef̂unden: bei Gruppe I $11 \mathrm{mal}$, bei Gruppe II $54 \mathrm{mal}$ und bei Gruppe III 19 mal. Phosphorsäure wurde in Gruppe I $10 \mathrm{mal}$, in Gruppe II 56 mal und in Gruppe III 30 mal gefunden. Eine Zusammenstellung der Befunde gibt die Tabelle III.

Tabelle III.

\begin{tabular}{|c|c|c|c|c|c|c|}
\hline & \multicolumn{3}{|c|}{ Gefunden in Brunnen der } & \multicolumn{3}{|c|}{ Gefunden in Proz. der Brunnen bei } \\
\hline & Gruppe I & Gruppe II & Gruppe III & Gruppe I & Gruppe II & Gruppe III \\
\hline Ammoniak & 1 & 7 & 5 & 4 & 7 & 14 \\
\hline Salpetrige Säure & 11 & 54 & 19 & 48 & 56 & 54 \\
\hline Phosphorsäure. & 10 & 56 & 30 & 43 & 58 & 86 \\
\hline
\end{tabular}


Auch hier dürfte das Bebauungsalter von EinfluB sein: für die Beurteilung sind jedenfalls alle diese Stoffe so gut wie wertlos.

Etwas besser, aber prinzipiell nicht anders als bei der chemischen Untersuchung liegen die Verhältnisse bei der in gewöhnlicher Weise angestellten, nur auf die Feststellung der Keimzahl sich beschränkenden bakteriologischen Untersuchung.

In der ersten Gruppe betrug der durchschnittliche Keimgehalt aller Untersuchungen 445, der geringste Keimgehalt wurde $\mathrm{zu} 6$, und der höchste zu 3000 gefunden. Die zweite Gruppe zeigte einen durchschnittlichen Keimgehalt von 2198, ein Maximum von 37000, ein Minimum von 25 Keimen. In der dritten Gruppe lauteten die Zahlen: 6815 für das Mittel, 190 für das Minimum und 46000 für das Maximum (s. Tabelle IV).

Tabelle IV.

\begin{tabular}{c||c|c|c}
\hline $\begin{array}{c}\text { Brunnen- } \\
\text { gruppe }\end{array}$ & Maximum & Minimum & Mittel \\
\hline I & 3000 & 6 & 445 \\
II & 37000 & 25 & 2198 \\
III & 46000 & 190 & 6815
\end{tabular}

Eine Beziehung zwischen der Beschaffenheit der Brunnen und dem Keimgehalt ist also nicht zu verkennen. Sämtliche Zahlen, Minimum, Maximum und Durchschnitt, steigen mit der abnehmenden Güte der Brunnen, besonders ist zwischen Gruppe I und II ein sehr beträchtlicher Unterschied vorhanden.

Auch wenn wir in den einzelnen Gruppen die Brunnen nach der Keimzahl ordnen, ähnlich wie wir es für den Chlorgehalt getan haben, tritt die Beziehung zwischen Keimzahl und Beschaffenheit sehr deutlich zutage (Tabelle V).

Tabelle $\nabla$.

\begin{tabular}{c||c|c|c|r|r|r|r}
\hline \multirow{2}{*}{ Keimzahl } & \multicolumn{2}{c|}{ Anzahl der Untersuchungen } & \multicolumn{2}{c}{ Prozente der Untersuchungen } \\
\cline { 2 - 7 } & Gr. I & Gr. II & Gr. III & Gr. I & Gr. II & Gr. III \\
\hline \hline $0-10$ & 2 & 0 & 0 & 6 & 0 & 0 \\
$11-50$ & 5 & 10 & 0 & 16 & 9 & 0 \\
$51-100$ & 3 & 10 & 0 & 9 & 9 & 0 \\
$101-200$ & 6 & 12 & 1 & 19 & 10 & 3 \\
$201-500$ & 6 & 22 & 4 & 19 & 19 & 11 \\
$501-1000$ & 6 & 18 & 7 & 19 & 15 & 20 \\
$1001-2000$ & 3 & 18 & 7 & 9 & 15 & 20 \\
$2001-5000$ & 1 & 13 & 5 & 3 & 11 & 14 \\
$5001-10000$ & 0 & 11 & 3 & 0 & 9 & 9 \\
$10001-20000$ & 0 & 1 & 5 & 0 & 1 & 14 \\
Über 20000 & 0 & 2 & 3 & 0 & 2 & 9
\end{tabular}


Nehmen wir beispielsweise die Zahl 1000 als Grenze an, so sind in Gruppe I 88 Prozent, in Gruppe II 62 Prozent und in Gruppe III 34 Prozent unter der Grenze. Unter 100 bleiben in Gruppe $I=31$, in Gruppe II $=18$, und in Gruppe III $=0$ Prozent.

Aber dieselben Zahlen zeigen auch hier aufs Deutlichste, daß diese Beziehungen nur ganz allgemeiner, gewissermaBen statistischer Natur sind, daB sie nur für grobe Versuchsreihen gelten können, daB aber für die Beurteilung des einzelnen Falles die Keimzahl nur ein höchst unsicherer Faktor ist. Es kommen gute Brunnen mit hohen und schlechte Brunnen mit niedrigen Keimzahlen vor; fast die Hälfte sämtlicher Brunnen lag bei allen drei Gruppen zwischen 200 und 2000 Keimen. Die Keimzahl ist eben außer von der Verunreinigung auch von der Benutzung des Brunnens abhängig, von der Zeit, die den Bakterien zur Vermehrung im Wasservorrat zur Verfügung steht.

Allenfalls lassen sich aus den extremen Zahlen gewisse Schlüsse ziehen. Sehr niedrige Zahlen, etwa unter 20, sprechen für, sehr hohe, etwa über 10000, sprechen gegen die Brauchbarkeit der Brunnen, normale Benutzung vorausgesetzt. Aber alles, was dazwischen liegt, hat für die Beurteilung nur sehr beschränkten Wert. Das sind dieselben Ergebnisse, zu denen Reichenbach bei einer ähnlichen Untersuchung gekommen ist. Auch Reichenbach kommt zu dem SchluB, daB bei einwandfreien Brunnen niedrige Keimzahlen, etwa bis 50, zu erwarten sind, daB aber bei mangelhaften Brunnen der Grad der Mangelhaftigkeit in keinem Verhältnis zu der Bakterienzahl stehe, und daB deshalb auch aus dem Bakteriengehalt eines Brunnens kein RückschluB auf seine Beschaffenheit gemacht werden könne.

$\mathrm{DaB}$ bei meinen 'Untersuchungen viele der einwandfreien Brunnen eine relativ hohe Keimzahl aufwiesen, rührt wohl davon her, daB sie selten benutzt wurden.

Und nun wollen wir den Coligehalt mit denselben Kriterien beurteilen.

Betrachten wir zunächst wieder die Durchschnittszahlen und das Maximum und Minimum (s. Tabelle VI).

Tabelle VI.

\begin{tabular}{c||c|c|c}
\hline \multirow{2}{*}{ Gruppe } & \multicolumn{3}{|c}{ Coli in 10 $\mathrm{ccm}$} \\
& Maximum & Minimum & Mittel \\
\hline I & 12 & 0 & $0 \cdot 67$ \\
II & 1568 & 0 & 66 \\
III & 6270 & 0 & 555
\end{tabular}


Das Minimum beträgt überall 0 , d. h. in jeder Gruppe kommen colifreie Brunnen vor, aber das Maximum und das Mittel zeigen ganz auBerordentlich große Differenzen. Besonders fällt der gewaltige Unterschied zwischen Gruppe I und II auf: das Mittel ist in Gruppe II $100 \mathrm{mal}$, das Maximum $130 \mathrm{mal}$ so grob wie in Gruppe I!

Natürlich ist damit, ebenso wie bei der Chlorbestimmung und der einfachen Keimzählung, noch nicht bewiesen, daB die Coliprobe auch für die Beurteilung des Einzelfalles brauchbar sei, aber die enorme Größe der Unterschiede legt doch von vornherein die Hoffnung nahe, daB auch hierfür die Colibestimmung sich anwenden lasse.

Betrachten wir nun wieder die Brunnen in jeder der drei Gruppen nach ihrem Coligehalt, so ergibt sich folgendes: In Gruppe I wurden 23 Brunnen untersucht, davon 10 zweimal, so daB also 33 Untersuchungen vorliegen. Von diesen scheiden zwei aus, weil der Brunnen lange nicht benutzt war, und deshalb die Pumpe mit nicht einwandfreiem Wasser angegossen werden mußte. Beide Male wurde Coli gefunden. Der eine der beiden Brunnen konnte einige Wochen später ohne Angießen untersucht werden und erwies sich dann als colifrei. In einem dritten Falle handelte es sich um einen ganz neu angelegten Brunnen. Auch bei diesem wurde Coli (100 in $10^{\mathrm{ccm}}$ ) gefunden, bei einer zweiten, 3 Monate darauf vorgenommenen Untersuchung war aber auch dieser frei von Coli.

Von den übrigen zweimal untersuchten Brunnen waren sieben beidemal colifrei, einer war einmal frei und enthielt das andere Mal drei Keime in $10^{\mathrm{cem}}$. Von den einmal untersuchten Brunnen waren 12 colifrei, nur zwei enthielten Coli und zwar der eine 12, der andere 11 Keime in $10 \mathrm{~cm}$.

Wir kommen also unter Berücksichtigung der angeführten Fehlerquellen, die zur Ausscheidung einiger Untersuchungen führen mußten, zu dem Resultat, dab in der Gruppe I bei 30 Untersuchungen an 21 Brunnen nur dreimal Coli gefunden wurde.

Betrachten wir zunächst nun die Resultate in der Gruppe III. Hier wurden 35 Brunnen untersucht, darunter 5 zweimal, so daB also 40 Untersuchungen vorliegen. Von diesen war nur eine einzige negativ, und auch diese betraf einen Brunnen, bei dem bei der zweiten Untersuchung Coli gefunden wurde. Es wurde also von sämtlichen Brunnen der Gruppe III kein einziger coliffrei befunden, und zwar waren die gefundenen Colimengen größtenteils recht beträchtlich.

In der Gruppe II wurde eine Anzahl von Brunnen colifrei, die meisten aber ebenfalls colihaltig gefunden. Es wurden 97 Brunnen untersucht, darunter 29 zweimal, die Gesamtzahl der Untersuchungen beträgt also 126. 
Colifrei waren bei zweimaliger Untersuchung 8 Brunnen; einmal colifrei, einmal colihaltig: 11 Brunnen; beidemal colihaltig: 10 Brunnen. Von den einmal untersuchten waren colihaltig 59, colifrei 9 Brunnen. Die Abstufung des Coligehaltes in den einzelnen Gruppen ist in Tabelle VII wiedergegeben.

Tabelle VII.

\begin{tabular}{|c|c|c|c|c|c|c|}
\hline \multirow{2}{*}{ Coligehalt in $10^{\mathrm{cem}}$} & \multicolumn{3}{|c|}{ Anzahl der Untersuchnngen } & \multicolumn{3}{|c|}{ Prozent der Untersuchungen } \\
\hline & Gr. I & Gr. II & Gr. III & Gr. I & Gr. II & Gr. III \\
\hline 0 & 27 & 36 & 1 & 90 & 29 & $2 \cdot 5$ \\
\hline $1-10$ & 2 & 40 & 4 & $6 \cdot 6$ & 32 & 10 \\
\hline $11-20$ & 1 & 10 & 3 & $3 \cdot 3$ & 8 & $12 \cdot 5$ \\
\hline $21-50$ & 0 & 12 & 5 & 0 & 10 & $12 \cdot 5$ \\
\hline $51-100$ & 0 & 8 & 2 & 0 & 6 & 3 \\
\hline $101-200$ & 0 & 7 & 8 & 0 & 6 & 20 \\
\hline $201-500$ & 0 & 11 & 6 & 0 & 9 & 15 \\
\hline $501-1000$ & 0 & 1 & 6 & 0 & 1 & 15 \\
\hline $1001-2000$ & 0 & 1 & 2 & 0 & 1 & 5 \\
\hline über 2000 & 0 & 0 & 3 & 0 & 0 & $12 \cdot 5$ \\
\hline
\end{tabular}

Welche Sehlüsse lassen sich nun aus diesem Befunde ziehen? Können wir wirklich im Gegensatz zu dem Verhalten von Chlor und Keimzahl aus dem Colibefund auch im einzelnen Falle auf die hygienische Beschaffenheit des Brunnens schließen? Ich glaube ja! Bei 22 äuBerlich einwandfreien Brunnen wurden in dreien Colibazillen in geringer Zahl gefunden, und umgekehrt war kein einziger der Brunnen, von dem man nach seiner äußeren Beschaffenheit annehmen mußte, daß er durch oberflächliche Zuflüsse verunreinigt werde (Gruppe III), colifrei. $\mathrm{DaB}$ in der Gruppe II der Befund stark wechselt, daB hier neben colihaltigen auch eine Anzahl colifreier vorkommen, lzann nicht wundernehmen. Denn hier handelt es sich ja um Brunnen, die zwar, soweit sich das äußerlich feststellen lieB, nicht absolut sicher gegen Verunreinigungen geschützt waren, bei denen aber das augenblickliche Bestehen einer Verunreinigung nicht sicher vorausgesetzt werden konnte. Hier $m u B$ also der jeweilige Zustand mehr oder weniger vom Zufall abhängig sein.

Die gröBte Schwierigkeit liegt in der Beantwortung der Frage, ob in denjenigen Fällen, in denen bei Gruppe I das Resultat der äuBeren Besichtigung nicht mit dem Colibefund im Einklang stand, in denen also äuBerlich einwandfreie Brunnen colihaltig gefunden wurden, $a b$ in diesen Fällen ein Versagen der Methode vorliegt, oder ob man schließen darf, daß hier Verunreinigungsmöglichkeiten existieren, die bei der Besichtigung nicht aufgefunden wurden. Die Antwort auf diese Frage wird im wesentlichen von der Anzahl der 
gefundenen Colikeime abhängen. Sind nur wenige Keime vorhanden, so wird man immerhin damit rechnen müssen, daß sie nicht aus dem Brunnen selbst stammen, sondern, daB sie durch Fehler bei der Entnahme, durch Berühren des Flaschenhalses durch Luftstaub, durch Beschmutzung des Pumpenausflusses, oder dergleichen, hineingekommen sind. Die Möglichkeit solcher Vorkommnisse wird man zugeben müssen, sehr häufig sind sie aber, wie wir später noch sehen werden, sicher nicht. Jedenfalls würde ich keinen Anstand nehmen, einen Brunnen, in dessen Wasser reichlich, etwa mehr als 20 in $10^{\mathrm{ccm}}$, Colibakterien gefunden werden, für verunreinigungsverdächtig zu erklären, auch wenn er äuBerlich durchaus einwandfrei erscheinen sollte.

Von den drei Brunnen der Gruppe I, die sich als colihaltig erwiesen hatten, war bei dem einen (Nr. 73), der 11 Colibazillen enthielt, die Zugehörigkeit zu dieser Gruppe nicht ganz sicher. Es handelte sich um einen Brunnen in einem Dorfe in der Nähe Göttingens, dessen Schacht unter der Tenne vollständig unzugänglich gelegen, und der nach Angabe der Besitzer durch eine Betonschicht abgedeckt war. Die Pumpe war seitlich vom Brunnen am Hause angebracht. Die Möglichkeit, daß die obere Abdeckung oder die obere Partie der Schachtwandung undicht waren, wird man also zugeben müssen.

Der zweite Brunnen besaB einen Schacht aus Zementringen und gab zu dem Verdacht einer Verunreinigung keinen AnlaB. Er war bei der ersten Untersuchung colifrei und enthielt bei der zweiten 3 Keime in $10^{\mathrm{ccm}}$. Hier würde ich ohne weiteres ein zufälliges Hineingelangen der Colikeime annehmen, wenn nicht bei der zweiten Untersuchung auch die Keimzahl sehr stark (von 560 auf 3000) sich gesteigert hätte. Auch war der Chlorgehalt beide Male außerordentlich hoch, 280 und $260 \mathrm{mg}$, ohne daB eine Erklärnng dafür sich hätte finden lassen. Eine Verunreinigung dieses Brunnens auf einem bei der Besichtigung nicht entdeckten Wege ist also keineswegs unmöglich. Eine nochmalige genauere Untersuchung konnte leider nicht vorgenommen werden.

Der dritte Brunnen endlich, in dem 6 Colikeime gefunden wurden, war durchaus einwandfrei. Hier haben wir es also wohl mit einem nachträglichen Hineingelangen der Keime zu tun.

Wenn wir danach von einem wírklich einwandfreien Brunnen erwarten. können, daB sein Wasser colifrei ist, und wenn wir also einen Brunnen, der ein stark colihaltiges Wasser liefert, ohne weiteres als verdächtig ansehen können, so muB doch andererseits dringend davor gewarnt werden, nun jeden B́runnen, in dessen Wasser kein Coli gefunden wird, für hygienisch unbedenklich zu erklären. 
Hier liegen die Grenzen der Methode. Sie kann uns, wie alle Methoden, die das Wasser untersuchen, im günstigsten Falle nur das Vorhandensein einer Verunreinigung, aber nicht die Möglichkeit einer solchen anzeigen. Wohl läßt sich, wie aus den Ergebnissen von Gruppe III hervorgeht, erwarten, dab ein sehr mangelhafter Brunnen auch colihaltig ist: das sind dann eben Brunnen, in die dauernd Verunreinigungen hineingelangen. Aber zwischen diesen und den ganz einwandfreien gibt es zahlreiche Zwischenstufen, bei denen die Möglichkeit der Verunreinigung vorhanden ist, bei denen es aber von allerhand Zufälligkeiten, insbesondere von den wechselnden meteorologischen Verhältnissen abhängt, ob zur Zeit der Untersuchung gerade die Verunreinigung besteht. Das sind die Brunnen der Gruppe II, und es kann deshalb nicht wundernehmen, wenn bei ihnen sehr verschiedene Coligehalte gefunden werden, und wenn auch bei ein und demselben Brunnen der Befund bäufig wechselt.

Wenn also ein Brunnen colifrei gefunden wird, so kann man mit ziemlicher Sicherheit annehmen, daß er nicht zur dritten Gruppe gehört, d. h., daB er nicht so schlecht ist, daß er dauernd der Verunreinigung ausgesetzt ist. $O \mathrm{~b}$ er aber ganz einwandfrei ist, läBt sich nicht sagen: hier maB die Ortsbesichtigung nach wie vor den Ausschlag geben. Andererseits kann aber die Coliprobe der Ortsbesichtigung unter Umständen darin überlegen sein, dab sie Wege der Verunreinigung aufdeckt, die bei der Ortsbesichtigung nicht gefunden werden.

\section{Untersuchang von Rammbrunnen.}

Die Vorbedingung für die Gültigkeit der eben entwickelten Anschauungen ist die, daB das Grundwasser an sich colifrei ist, rorausgesetzt natürlich, daß der Boden genügende filtrierende Kraft besitzt. Unter „colifrei“, das möchte ich, um jedes Mißverständnis auszuschlieBen, auch hier noch einmal ausdrücklich betonen, ist selbstverständlich im Sinne meiner einleitenden Ausführungen zu verstehen, daB mit der von mir benutzten Methodik und in der von mir untersuchten Wassermenge keine Colibazillen gefunden werden.

Aus den in der Gruppe I gewonnenen Resultaten läßt sich nun mit einiger Sicherheit entnehmen, daB diese Voraussetzung zutrifft. Immerhin wāre, bei der nicht allzu großen Anzahl dieser Untersuchungen, eine Bestätigung durch weitere Untersuchungen am Grundwasser selbst wünschenswert. Theoretisch würde dazu nötig sein, das Grundwasser mit sterilisierten Rohren, sterilisierter Pumpe usw. zu entnehmen. Von diesem Vorgehen muBte ich wegen seiner Umständlichkeit absehen, es war aber 
zu hoffen, daB die Untersuchung der in Göttingen ziemlich zahlreich vorhandenen Rammbrunnen einen Ersatz bieten könne. Ist doch bei einem nicht ganz neuen, gut angelegten Rammbrunnen eine Verunreinigung von oben her so gut wie ausgeschlossen. Ein Hineingelangen von Coli ist nur möglich durch die obere Offnung der Pumpe oder durch das AusfluBrohr, also durch den Luftstaub oder durch Berührung mit den Händen: beides Wege, die keine große Wahrscheinlichkeit für sich haben. Wir können deshalb im allgemeinen erwarten, dab ein Rammbrunnen, wenn das Grundwasser colifrei ist, es auch colifrei abliefern wird.

Die Untersuchung der Rammbrunnen wurde sehr erschwert durch den Umstand, daß bei den meisten von ihnen das Saugrentil der Pumpe nicht mehr ganz einwandfrei funktionierte, so daB das Wasser aus dem Saugrohr ablief. Um die Pumpe in Gang zu setzen, muBte deshalb von oben her Wasser eingegossen werden. Dieses "AngieBen" geschah, wenn ich dabei war, meistens mit Leitungswasser, und zwar mit möglichst sauberen Gefäßen; da aber auch in meiner Abwesenheit von den Besitzern die Brunnen in Gang gesetzt wurden, läßt sich weder für die Beschaffenheit des Wassers, noch für die Gefäße in allen Fällen eine Garantie übernehmen. Das Hineingelangen von Coli war also bei diesen Brunnen nicht ausgeschlossen, doch war zu erwarten, dab bei dem geringen Wasservorrat der Rammbrunnen ein kräftiges Abpumpen zum Fortspülen dieser Verunreinigungen genügen werde.

Es scheint aber trotzdem zweckmäßig, die angegossenen und die nicht angegossenen Brunnen getrennt aufzuführen. Im ganzen wurden 53 Rammbrunnen untersucht; davon nicht angegossen 15, angegossen 38. Von den nicht angegossenen wurden untersucht: 1 Brunnen viermal, 3 Brunnen dreimal, 5 Brunnen zweimal und 6 Brunnen einmal. Bei diesen 29 Untersuchungen wurden nur zweimal Coli gefunden, und zwar einmal 2, das andere Mal 4 Keime. Der erste Befund betrifft einen Brunnen, der eine Kombination von Schacht- und Rammbrunnen darstellte, das Saugrohr war noch ein Stück - wie tief, konnte ich nicht feststellen - in den Boden des Schachtes gerammt. Der Schacht war wasserleer, möglicherweise konnten aber doch Verunreinigungen am Saugrohr hinunter und in die wasserführende Schicht gelangen. Der zweite Brunnen wurde zweimal untersucht; einmal war er colifrei, das andere Mal enthielt er 4 Colikeime. Auch die Keimzahl, die bei der ersten Untersuchung 4 betragen hatte, war bei der zweiten auf $\mathbf{5 8 0}$ in die Höhe gegangen. Er stand ganz unmittelbar neben einer Dungstätte, so daB die Möglichkeit einer oberirdischen oder unterivdischen Verunreinigung nicht ausgeschlossen ist. Auch muB natürlich mit der Möglichkeit gerechnet werden, daB dieser 
Brunnen in meiner Abwesenheit gelegentlich einmal von dem Besitzer durch AngieBen in Gang gesetzt wurde.

Im übrigen war aber das Wasser der nicht angegossenen Rammbrunnen colifrei, und damit gewinnt die Annahme von der Colifreiheit des Grundwassers eine wesentliche Stütze.

Die Keimzahl war bei den Rammbrunnen verhältnismäBig niedrig, sie schwankte, wenn wir das eben erwähnte einmalige Vorkommen von 580 Keimen ausscheiden, zwischen 2 und 170 und betrug im Mittel 33.

Nicht ganz so beweisend, aber immerhin doch sehr deutlich waren die Resultate bei den angegossenen Rammbrunnen. Da das Angießen immer eine Verunreinigung im bakteriologischen Sinne bedentet, muBte von vornherein mit dem Vorhandensein von Coli gerechnet werden. Trotzdem war auch hier die gröBte Mehrzahl der Brunnen colifrei.

Es wurden im ganzen 38 angegossene Rammbrunnen untersucht, davon:

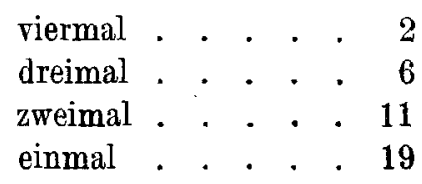

so daB also im ganzen 67 Untersuchungen vorliegen. Von diesen ergaben 46, also 68 Prozent, kein Coli!

Tabelle VIII.

\begin{tabular}{c|c|c}
\hline \multirow{2}{*}{ Coli in 10 ccm } & \multicolumn{2}{|c|}{ Zahl der Untersuchungen } \\
& absolut & Prozent \\
\hline 0 & 46 & 69 \\
1 & 9 & 13 \\
$2-5$ & 5 & 7.5 \\
$6-10$ & 2 & 3 \\
$11-20$ & 1 & 1.5 \\
$21-50$ & 2 & 3 \\
$51-76$ & 2 & 3
\end{tabular}

Die Häufigkeit der einzelnen Colizahlen bei den angegossenen Brunnen zeigt Tabelle VIII. Wir sehen daraus, daB der Coligehalt meistens sehr gering war und nur aus vereinzelten Keimen bestand, in 90 Prozent der Fälle betrug er nur 0 bis 5 . Ein Coligehalt von über 20 wurde nur viermal gefunden, und ron diesen vier Untersuchungen betreffen zwei einen Brunnen, von dem sich später herausstellte, daB es ein Schachtbrunnen mit zugeschüttetem Schacht, also überhaupt kein eigentlicher Rammbrunnen 


\section{Untersuchungen von Bodenproben.}

Nach den bisherigen $A$ usführungen kann angenommen werden, daß einwandfreie Brunnen in der Regel ein colifreies Wasser liefern, und daB jeder irgendwie beträchtliche Coligehalt auf den Zufluß unfiltrierten Wassers hinweist. Die an den Rammbrunnen gewonnenen Ergebnisse sprechen weiter dafür, daß diese Zuflüsse von oben her in den Brunnen gelangen, und daß wenigstens in der Regel ein Hineingelangen von Coli ins Grundwasser nicht vorkommt. Fine Prüfung der Richtigkeit dieser Auffassung schien mir möglich zu sein durch Untersuchungen über die Verbreitung des Bacterium coli im Boden und insbesondere über sein Vorkommen in verschiedenen Tiefen. Ich habe deshalb eine ganze Anzahl von Bodenproben aus verschiedener Umgebung und aus verschiedenen Tiefen auf das Vorhandensein von Bacterium coli untersucht. Die Technik muBte bei diesen Versuchen etwas abgeändert werden. Denn das Plattenverfahren, das sich bei den Wasseruntersuchungen ausgezeichnet bewährt hatte, versagte hier dadureh, daB bei den Bodenproben sowohl auf Drigalski- wie auf Endoagar eine so große Zahl anderer Keime sehr üppig sich ausbreitete, daB dadurch das Wachstum der Colibakterien beeinträchtigt wurde. Bei den Endoplatten kam auBerdem noch hinzu, daß sie durch die Begleitbakterien in ihrer ganzen Ausdehnung rot gefärbt wurden und dadurch einzelne Colikolonien schwer erkennen ließen.

Es gelang deshalb sehr häufig nicht, aus Bodenproben, in denen man ihr Vorhandensein sicher vermuten konnte, die Colibakterien zu züchten. So mußte also auf das Anreicherungsverfahren zurückgegriffen werden. Als Anreicherungsflüssigkeit habe ich eine 1 prozentige Tranbenzuckerbouillon benutzt. Die Bodenproben wurden mit etwas Bouillon gründlich geschüttelt, und von der Aufschwemmung $1 / 2$ bis 1 com zu den mit 50 com gefüllten Bouillonkölbchen hinzugesetzt. Die in den Kölbchen gewachsenen Bakterien wurden dann auf Endoplatten näher untersucht. Wahrscheinlich liefert auch das Anreicherungsverfahren, wenigstens bei den oberflächlichen Proben, noch zu niedrige Werte, da auch hier die Gefahr der Ūberwucherung einzelner Colikeime durch die sehr zahlreichen Begleitbakterien besteht. Nicht selten gingen auf den Endoplatten nur wenige Colikolonien an.

Die Erdproben wurden von der Oberfläche direkt, aus den tieferen Sehichten mittels des Fränkelschen Bohrers entnommen. Der Bohrer wurde nach jedem Gebrauch so gut wie möglich durch Abwischen mit 5 prozentiger Karbolsäure gereinigt.

Zunächst habe ich auf diese Weise oberflächliche Bodenproben aus der Umgebung von colihaltigen Brunnen untersucht. Von 23 solehen 
Untersuchungen waren 18 positiv, 5 negativ. Weitere 7 Proben wurden auf Ackerfeldern entnommen, von diesen waren 5 positiv. Die Verteilung der Keime nach der Tiefe zu gibt Tabelle IX. Man sieht, wie der Coligehalt nach der Tiefe zu rasch abnimmt, wie aber doch beträchtliche TnregelmäBigkeiten den gesetzlichen Verlauf der Abnahme stören. Es liegt nahe, anzunehmen, daB diese UnregelmäBigkeiten auf die Art der Entnahme zurückzuführen sind: daß entweder die Reinigung des Bohrers nicht genügend war, oder daB beim Durchdringen der colihaltigen Bodenschichten Keime mit in die Tiefe genommen wurden.

Tabelle IX.

\begin{tabular}{c||c|c|c}
\hline \multirow{2}{*}{ Tiefe } & Zahl & \multicolumn{2}{|c}{ Davon: } \\
& der Proben & positiv & negativ \\
\hline Oberfläche & 23 & 18 & 5 \\
$0 \cdot 3^{\text {m }}$ & 1 & 0 & 1 \\
$0 \cdot 6$, & 2 & 0 & 2 \\
$1 \cdot 0$, & 24 & 4 & 20 \\
1.5, & 17 & 8 & 9 \\
1.8, & 30 & 1 & 29 \\
$2 \cdot 0$, & 30 & 2 & 28
\end{tabular}

Eine Gelegenheit, die Versuche mit Vermeidung dieses Fehlers anzustellen, bot sich mir dadurch, daB auf einem Ackerfelde in der Nähe der Stadt Aufgrabungen zum Zweck der Erweiterung der Wasserversorgung angestellt wurden. Es wurden Schächte bis zu einer Tiefe von $6^{\mathrm{m}}$ hergestellt, und aus den Seitenwänden dieser Schächte konnte ich unter Vermeidung der äußersten Schicht die Proben entnehmen. Der Keimgehalt von 88 so entnommenen Proben ist in Tabelle $\mathrm{X}$ wiedergegeben.

Hier tritt das Resultat viel reiner hervor: tiefer als $0.7^{\mathrm{m}}$ war überhaupt kein Coli mehr nachzuweisen. Allerdings muB dabei berücksichtigt werden, daB der Ackerboden nicht so stark mit Coli durchsetzt sein wird, wie der Boden in den engen, meist stark verunreinigten Höfen. Jedenfalls läBt sich aus diesen Untersuchungen aber entnehmen, daB es die Oberfläche des Bodens und die allerobersten Schichten sind, in denen das Coli sich findet, und daB sein Vorkommen in den Brunnen deshalb auf Beimengungen aus diesen Schichten beruht. Dabei ist natürlich, das mag. noch einmal ausdrücklich betont werden, normale filtrierende Wirkung des Bodens vorausgesetzt. DaB im lockeren Boden oder spaltenreichen Gestein auch einmal die Colibakterien bis zum Grundwasser vordringen können, soll selbstverständlich nicht bestritten werden. Im Gegenteil: der Nachweis von Coli in dem Wasser eines 
Tabelle $\mathrm{X}$.

\begin{tabular}{|c|c|c|c|}
\hline \multirow{2}{*}{ Tiefe } & \multirow{2}{*}{$\begin{array}{c}\text { Zahl } \\
\text { der Proben }\end{array}$} & \multicolumn{2}{|c|}{ Davon: } \\
\hline & & positiv & negativ \\
\hline Oberfläche & 7 & 5 & 2 \\
\hline $0 \cdot 1 \mathrm{~m}$ & 4 & 2 & 2 \\
\hline 0.2, & 8 & 1 & 7 \\
\hline $0 \cdot 3$, & 4 & 2 & 2 \\
\hline 0.4 & 8 & 1 & 7 \\
\hline $0 \cdot 5 .$, & 2 & 1 & 1 \\
\hline 0.6, & 7 & 1 & 6 \\
\hline 0.7, & 3 & 1 & 2 \\
\hline 0.8, & 5 & 0 & 5 \\
\hline 0.9, & 3 & 0 & 3 \\
\hline $1 \cdot 0$, & 6 & 0 & 6 \\
\hline $1 \cdot 2$, & 10 & 0 & 10 \\
\hline $1 \cdot 4$, & 4 & 0 & 4 \\
\hline 1.5, & 5 & 0 & 5 \\
\hline $1.6-6 \cdot 0^{\mathrm{m}}$ & 12 & 0 & 12 \\
\hline
\end{tabular}

gegen oberflächliche Verunreinigungen sicher gut geschützten Brunnens würde für die Beurteilung des Grundwassers und der Bodenverhältnisse von groBer Bedeutung sein.

Reichenbach hat solche Brunnen erwähnt: es handelte sich um äuBerlich durchaus einwandfreie Rammbrunnen, die auch nach langem Abpumpen dauernd ein sehr keimreiches Wasser lieferten. Sie lagen in unmittelbarer Nähe des Leinekanals und standen wahrscheinlich unterirdisch mit $\mathrm{ihm}$ in Verbindung. Hätte man diese Brunnen damals auf Coli untersucht, so würde man höchstwahrscheinlich einen reichlichen Coligehalt gefunden haben. Ich selbst habe aber solche von unten her verunreinigte Brunnen nicht sicher nachweisen können.

\section{Untersuchungen ron Quellen.}

Obwohl eine genaue Untersuchung des Coligehaltes ron Quellwasser eigentlich nicht im ursprünglichen Plan meiner Arbeit lag, möchte ich doch hier kurz einige Untersuchungsresultate mitteilen, die ich bei Gelegenheit der Besichtigung auswärtiger Brunnen an Quellen gewonnen habe. Es handelte sich meist um gar nicht oder sehr primitiv gefaBte, aus Kalkstein entspringende Quellen. Kine Beimengung von Oberflächenwasser war daher trotz aller Sorgfalt nicht immer zu vermeiden.

Es wurden im ganzen 35 Quellen untersucht, und zwar 3 von ihnen dreimal, 12 zweimal, so daB im ganzen 53 Untersuchungen vorliegen. 
Das Resultat war folgendes:

Dreimal untersucht: 3 Quellen, davon dreimal colifrei: 1, zweimal colifrei: 2 ;

zweimal untersucht: 12 Quellen, davon zweimal colifrei: 9, einmal colifrei: 3, zweimal colihaltig: 0 ;

einmal untersucht: 20 Quellen, davon colifrei: 15, colihaltig: 5 .

Es wurden also bei 53 Untersuchungen zehnmal Colibakterien gefunden. Die Anzahl war aber meist sehr gering; das Nähere gibt Tabelle XI. GroBe Colizahlen (über 20 ) waren also nur bei 2 Untersuchungen vorhanden: davon betraf die eine eine dreimal untersuchte Quelle, die bei den anderen Untersuchungen colifrei gewesen war, und die andere eine zweimal untersuchte, die ebenfalls das Mal vorher ein colifreies Wasser geliefert hatte. $\mathrm{Ob}$ bei diesen Quellen die gefundenen Colikeime aus dem Quellwasser selbst stammten, oder ob sie sich ihm erst nach seinem Austritt durch oberflächliche Zuflüsse beigemengt hatten, vermag ich, da es sich um ungefaBte Quellen handelte, nicht zu sagen. So viel geht jedenfalls aus den Beobachtungen hervor, daB sogar bei ungefaßten Quellen das Vorkommen von Coli keineswegs häufig, geschweige denn allgemein ist, dab also eine Prüfung des Coligehaltes keineswegs ein überflüssiges Beginnen ist. Auf seine Bedeutung für die hygienische Beurteilung der Quellen werde ich später noch kurz zurückkommen.

Tabelle XI.

\begin{tabular}{c||c|c}
\hline Coli in 10 & \multicolumn{2}{c|}{ Zahl der Untersuchungen } \\
\hline 0 & absolut & Prozent \\
\hline $1-5$ & 43 & 81 \\
$6-10$ & 6 & 11 \\
$11-20$ & 0 & 0 \\
$21-50$ & 2 & 4 \\
über 50(72) & 1 & 2 \\
\end{tabular}

Hier nur noch einige Worte über die Gesamtkeimzahl und den Chlorgehalt der Quellen. Der Gehalt an Bakterien war sehr wechselnd. Er lag zwischen 6000 und 3 und betrug im Durchschnitt 462. Der höchste Keimgehalt (6000) fiel mit dem höchsten Coligehalt zusammen, im übrigen aber gingen die beiden Zahlen keineswegs parallel. Auch bei colifreien Quellen kamen sehr hohe Keimzahlen vor (1500, 3720), während umgekehrt keimarme Quellen Coli enthielten. 
Tabelle XII.

\begin{tabular}{c||c|c}
\hline $\begin{array}{c}\text { Quelle } \\
\text { Nr. }\end{array}$ & $\begin{array}{c}\text { Keimgehalt } \\
\text { in 1 ccm }\end{array}$ & Coli in $10^{\mathrm{ccm}}$ \\
\hline 3 & 60 & 0 \\
& 910 & 0 \\
& 6000 & 72 \\
6 & 70 & 0 \\
& 220 & 22 \\
13 & 450 & 1 \\
& - & 0 \\
16 & 11 & 2 \\
24 & 230 & 0 \\
& 72 & 4 \\
27 & 57 & 0 \\
& 280 & 15 \\
31 & 100 & 3 \\
32 & 10 & 2 \\
34 & 4200 & 20 \\
35 & 27 & 2
\end{tabular}

In der Tabelle XII sind für die colihaltigen Quellen Keimzahlen und Colizahlen nebeneinandergestellt. Man sieht, wie besonders bei den mehrfach untersuchten Quellen die Verunreinigung meistens auch im Keimgehalt zum Ausdruck kommt, wie aber (Nr. 24) die Sache sich auch umgekehrt verhalten kann. Zufälligkeiten spielen selbstverständlich bei den ungefaßten Quellen eine groBe Rolle.

Der Chlorgehalt war durchweg niedrig, er lag zwischen 6 und $40 \mathrm{mg}$ und betrug im Durchschnitt 14.6 mg. Irgendwelche Beziehungen zwischen Chlorgehalt und Colivorkommen waren nicht zu erkennen. Zufällig waren gerade die Quellen mit dem gröBten Chlorgehalt colifrei, während die colireichsten Quellen sehr niedrigen Chlorgehalt zeigten.

\section{Die Art der gefundenen Colistämme.}

Wenn in den bisherigen Ausführungen von Coli schlechtweg die Rede gewesen ịst, so sind damit Stämme gemeint, die den auf S. 201 angeführten Anforderungen entsprachen. Nur diese sind als Coli angesehen, und nur Wässer mit solchen Stämmen sind als colihaltig bezeichnet worden.

Wie steht es nun aber mit dem Vorkommen sogenannter atypischer Stämme? Man könnte darüber streiten, ob überhaupt der Ausdruck ,atypisches Coli“ zulässig ist. Es erscheint zunächst rationeller, die Bezeichnung Coli nur für solche Bakterien zu reservieren, die alle verlangten Eigenschaften aufweisen, und alle abweichenden Stämme überhaupt nicht 
als Coli, sondern mit irgendeinem anderen Namen zu bezeichnen. Praktisch wird sich das aber kaum durchführen lassen. Denn vom echten durchaus typischen Coli bis zum Bacillus alcaligenes, den wohl kaum noch jemand als Coli bezeichnen möchte, gibt es eine ununterbrochene Reihe von Ubergängen, und zwar nicht nur in qualitativer, sondern auch in quantitativer Hinsicht. Es gibt Stämme, die wohl Milchzucker zersetzen, aber viel weniger Säure bilden als die anderen Arten; andere, bei denen die Fähigkeit zur Gasbildung aus Traubenzucker wohl vorhanden, aber sehr schwach entwickelt ist, und endlich solche, die das Neutralrot nur sehr langsam und unvollkommen reduzieren. Für diese Stämme wird man die Bezeichnung des atypischen Coli nicht gut entbehren können; eine gewisse Willkür in der Abgrenzung wird sich aber nie vermeiden lassen, und es ist deshalb unerläBlich, daB jeder Autor genau angibt, was er unter atypischem Coli versteht.

$\mathrm{Da}$.wir von vornherein als unerläßliche Eigenschaften am Coli die Milchzuckerzersetzung postuliert haben und Stämme ohne diese Fähigkeit überhaupt nicht als Coli ansehen, ist der Begriff des atypischen Coli für uns von vornherein ziemlich eng begrenzt. Es kann sich nur um solche Stämme handeln, bei denen eine der anderen Eigenschaften, Gasbildung auf Traubenzucker, typisches Verhalten gegen Neutralrot, Beweglichkeit usw., fehlt oder nur sehr schwach vorhanden ist. Fraglich erschien es, ob man auch die quantitative Säurebildung nach den auf S. 202 auseinandergesetzten Prinzipien als Merkmal des typischen Coli ansehen sollte. Ich habe mich vorläufig nicht dazu entschließen können, sondern habe Stämme, die nur durch geringere Säurebildung abwichen, im übrigen aber sich typisch verhielten, als typisches Coli angesehen.

Stämme, die bei normaler Säurebildung in anderen Eigenschaften sich atypisch verhielten, habe ich nicht gefunden. Die quantitative Säurebildung scheint also diejenige Eigenschaft zu sein, in der sich die Abweichung vom Typus zuerst geltend macht.

Es ergeben sich also für uns drei Kategorien:

1. Echtes Coli mit den programmäßig geforderten Eigensehaften und einer Säurebildung über 2.0 (meistens 2.5 bis 2.7 ).

2. Echtes Coli, aber mit schwacher Säurebildung (meistens 1.5 bis 2.0). Auf diese beiden Arten beziehen sich die gesamten Angaben über Vorkommen von Coli in Wässern.

3. Atypisches Coli, zersetzt Milchzucker, weicht aber in einer anderen Eigenschaft qualitativ oder stark quantitativ vom Typus ab. Die Säurebildung ist gewöhnlich sehr schwach (unter 1.5, meistens unter 1). 
Angaben über das Vorkommen dieser drei Kategorien in den untersuchten Wässern können natürlich nur einen relativen Wert beanspruchen. Denn selbstverständlich war es nicht möglich, alle Colikolonien zu untersuchen; man mußte sich damit begnügen, aus den zum Teil sehr zahlreichen Kolonien eine oder einige charakteristische herauszusuchen, die der Mehrzahl der vorhandenen entsprach. Da alle Stämme, die Milchzucker nicht zersetzten, von vornherein auszuschließen waren, wurden nur Kolonien berücksichtigt, die auf Drigalskiagar deutliche Rötung, auf Endo deutlichen Fuchsinglanz zeigten. Auf diese Weise wird der größte Teil der von anderen Autoren sogenannten atypischen Coli, d. h. der Stämme ohne Milchzuckerzersetzung, die wir nicht zum Coli rechnen, ausgeschlossen. Ich habe nur einen einzigen Stamm gefunden, der trotz deutlichen Fuchsinglanzes Milchzucker nicht zu zersetzen vermochte. Auf Drigalskiagar wuchs dieser Stamm dementsprechend blau: worauf sein Verhalten auf Endoagar beruht, ist nicht aufgeklärt und muB noch weiter untersucht werden.

Im übrigen aber hat sich auch hier die schon von mehreren Seiten gemachte, besonders von Schürer betonte Beobachtung bestätigt, daB Stämme mit deutlichem Fuchsinglanz auch meistens typische Colistämme sind. Unter 238 untersuchten Stämmen habe ich nur zwölf gefunden, die als atypisches Coli in unserem Sinne angesprochen werden mubten. Sie wichen meistens durch ihr Verhalten im Neutralrotagar, selten in der Gasbildung vom Typus ab.

Sehr viel häufiger $(67 \mathrm{mal})$ wurde die zweite Kategorie, die typischen, aber schwach säurebildenden Stämme getroffen.

In der Verteilung der abweichenden Stämme auf die einzelnen Fundorte ergaben sich nun verschiedene bemerkenswerte Einzelheiten.

Aus Rammbrunnen - wurden 20 Stämme geprüft, davon waren 15 typisch, 2 atypisch und 3 typisch mit schwacher Säurebildung. Von 15 aus Quellen gezüchteten Stämmen waren 13 typisch, 2 atypisch.

Aus Schachtbrunnen wurden 156 Stämme untersucht; davon gehörten 125 zur ersten Kategorie, 24 differierten nur in der Säurebildung und 7 waren atypisch. Dabei ist höchst bemerkenswert, daB in der dritten Brunnengruppe kein atypischer Stamm und nur ein einziger schwacher Säurebildner angetroffen wurde. Mit anderen Worten, bei den schlechten Brunnen wurde mit einer Ausnahme nur vollständig typisches Coli gefunden.

Das gerade Gegenteil ergab sich bei der schon früher erwähnten Untersuchung der Göttinger Wasserleitung, als nach Inbetriebnahme eines neuen Behälters eine Zeitlang das Wasser täglich auf Coli untersucht wurde. Das sonst absolut colifreie Wasser enthielt jetzt lange Zeit (länger 
als 7 Wochen) hindurch Coli. Von 47 untersuchten Stämmen besaßen aber nur 7 volle Säurebildung, während 40 schwache Säurebildner waren, im übrigen aber sich typisch verhielten.

Im Zusammenhang mit dieser Beobachtung möchte ich das Verhalten der aus Bodenproben isolierten Stämme erwähnen. Im ganzen wurden 43 Stämme geprüft. Ihr Verhalten gibt die folgende kleine Tabelle:

\begin{tabular}{|c|c|c|c|}
\hline \multirow{2}{*}{ Tief $\theta$} & \multirow{2}{*}{$\begin{array}{c}\text { Zahl } \\
\text { der geprüften } \\
\text { Stämme }\end{array}$} & \multicolumn{2}{|c|}{ Säurebildang } \\
\hline & & unter $\boldsymbol{2} \cdot 0$ & über $2 \cdot 0$ \\
\hline Oberfläche & 19 & 4 & 15 \\
\hline Bei $0.5^{\mathrm{m}}$ & 10 & 5 & 5 \\
\hline Unter $0 \cdot 5^{\text {m }}$ & 14 & 8 & 6 \\
\hline
\end{tabular}

Man sieht also deutlich, wie nach der Tiefe zu das Säurebildungsvermögen der gefundenen Stämme abnimmt.

Können wir nun aus diesen Tatsachen irgendwelche Schlüsse auf die Bedeutung der verschiedenen Coliarten ziehen? Wenn wir zunächst die Verteilung im Boden berücksichtigen, so könnte man sie vielleicht so deuten, dab ein längerer Aufenthalt im Boden die Säurebildungsfähigkeit des Coli heruntersetzt. Die in der Tiefe gefundenen schwachen Säurebildner wären danach als ursprünglich typische, aber durch den Aufenthalt im Boden abgeschwächte Stämme anzusehen, und der Nachweis solcher Stämme würde nicht auf eine frische Beimengung von Fäkalien, sondern auf eine vor längerer Zeit erfolgte Verunreinigung hindeuten. Ja noch mehr! Nach den bislang vorliegenden Erfahrungen können wir uns nicht gut vorstellen, daB sich die Veränderung der Eigenschaften eines Bacteriums an ein und demselben Individuum vollziehe: eine Vermehrung ist also nötig, wenn die Abschwächung der Säurebildung eintreten soll. Eine Möglichkeit der Vermehrung im Erdboden, unter günstigen Umständen wenigstens, wird sich nicht leugnen lassen -, wir müBten also annehmen, daB die schwach säurebildenden Colistämme überhaupt nicht selbst den Darm passiert haben, sondern daB nur ibre mehr oder weniger weit entfernten Vorfahren aus dem Darm stammten, während sie selbst schon im Boden entstanden sind.

Ähnliche Uberlegungen lassen sich auch mit Bezug auf die im Wasser gefundenen atypischen Formen anstellen. Auch hier wird man die Möglichkeit einer Vermehrung und damit ihre Entstehung im Wasser selbst nicht ganz leugnen können. Häufiger werden sie aber wohl aus dem Boden stammen und mit oberflächlichen Zuflüssen ins Wasser hineingelangen. 
Was hier über die schwach säurebildenden Stämme gesagt worden ist, gilt natürlich im erweiterten $M a B e$ für die eigentlichen atypischen Coliarten. Auch sie können aus echtem Coli hervorgegangen sein, nur, $d a B$ es von ihnen noch viel zweifelhafter ist, ob es sich so verhält, und $\mathrm{daB}$ wahrscheinlich noch längere Zeiträume für die Umwandlung nötig sind. Auch mit der Möglichkeit, daß es sich um Tiercoli handelt, die sich abweichend vom Menschencoli verhalten, muB gerechnet werden.

Wie dem aber auch sei, so viel ist jedenfalls sicher, dab alle diese Stämme einen Wert als Indikator für eine frische Fäkalverunreinigung nicht besitzen können. Sie würden sich in dieser Hinsicht kaum von den übrigen Wasser- und Bodenbakterien unterscheiden. Denn zweifellos sind zu ihrer Entstehung längere Zeiträume (Monate) erforderlich. Sie können aber auch vor noch längerer Zeit den Darm verlassen haben, sie können auf weite Strecken passiv — vielleicht auch aktiv durch eigenes Wachstum - verbreitet werden, so daB jeder für die Beurteilung verwertbare Zusammenhang mit ihrer Ursprungsstätte aufgehört hat.

Lassen sich nun die tatsächlichen Beobachtungen mit diesen Anschauungen von der Bedeutung der atypischen Colistämme vereinigen?

Was zunächst die Erfahrungen an den Brunnen anlangt, so scheint der Umstand, daß bei den Brunnen der Gruppe III ausschlieBlich bis auf eine Ausnahme typisches Coli gefunden wurde, entschieden für ibre Richtigkeit zu sprechen. Das sind eben Brunnen, die der Ursprungsstätte des Coli so nahe sind, und die dauernd oder doch so häufig verunreinigt werden, daB immer frisches unverändertes Coli vorhanden ist. In der Gruppe II dagegen, wo neben viel unverändertem auch atypisches Coli oder gar keins gefunden wurde, hängt die Art und die Häufigkeit der Verunreinigungen vom Zufall ab, und daraus erklären sich die wechselnden Befunde.

Auch die Beobachtungen an der Wasserleitung lassen sich in unserem Sinne deuten. In dem Wasser des neuen Reservoirs wurde in überwiegender Häufigkeit ein schwach säurebildendes Bacterium gefunden. Frische Fäkalverunreinigungen sind hier wohl so gut wie ausgeschlossen, dagegen ist ein Hineingelangen von Erdboden in die Rohrleitung sowohl wie in den Behälter nicht gut zu vermeiden.

Ich möchte es aber ablehnen, allen diesen Gedankengängen gar zu weit nachzugehen, und möchte mich vor allen Dingen ausdrücklich gegen die Auffassung verwahren, daB ich diese vorläufig rein hypothetischen Anschaungen als erwiesen betrachte. Zur experimentellen Begründung fehlt uns vorläufig noch so 
gut wie jede Unterlage: wir wissen fast nichts über die Veränderlichkeit der Colibakterien; auch ihre Haltbarkeit und ihre Vermehrungsfähigkeit im Boden und im Wasser bedürfen noch sehr der Untersuchung. Ebenso müssen auch die feineren biologischen Unterschiede zwischen Mensehenand Tiercoli studiert werden.

\section{Schlnßbetrachtungen und Zusammenfassung.}

An die Spitze dieser Betrachtungen können wir den Satz stellen, daB das Bacterium coli ein wasserfremder Organismus ist. Normales Grundwasser ist colifrei: der Befund von Coli im Grundwasser deutet deshalb auf eine Verunreinigung durch oberflächliche Zuflüsse oder durch ungenügende Filtration hin. Man könnte nun sofort geltend machen, daß dieselbe Überlegung auch auf die gewöhnliche Keimzählung zutreffe, daß deshalb oberfächliche Zuflüsse auch durch das Ansteigen der Keimzahl erkannt werden müssen. Tatsächlich ist das ja auch bis zu einem gewissen Grade der Fall; aber wie unzuverlässig dieses Kriterium ist, geht zur Genüge aus den mitgeteilten Zahlen hervor.

Der Grund für die große Überlegenheit der Coliprobe bei Brunnen liegt darin, daB seine Vermehrungsfähigkeit im Wasser beschränkt und seine Lebensdauer deshalb nur kurz ist. Die Probe wird dadurch in viel höherem MaBe als die Keimzählung unabhängig von der Intensität der Benutzung des Brunnens. In wenig benutzten Brunnen kann die Keimzahl, auch wenn keine verunreinigenden Zuflüsse vorhanden sind, eine außerordentliche Höhe erreichen, die durch Abpumpen wohl verringert, aber nicht auf die Norm zurückgeführt werden kann. Eine hohe Keimzahl braucht deshalb noch keine Verunreinigung von oben zu beweisen; der Befund von Coli spricht immer für eine solche, abgesehen vielleicht von den Fällen, wo ganz vereinzelte Keime gefunden werden, die durch einen Fehler bei der Entnahme hineingekommen sein können.

Daß umgekehrt das Freisein eines Brunnens von Coli keinen sicheren Beweis für seine einwandfreie Beschaffenheit bietet, ist schon auf S. 213 eingehend auseinandergesetzt worden. So viel wird man aber sagen können, daB ein Brunnen, der bei wiederholten Untersuchungen, auch nach starken Regengüsssen, kein Coli enthält, nicht ganz schlecht sein kann und nicht unmittelbar gefährdet ist. 
Die Bedeutung des Coli für den Nachweis oberflächlicher Verunreinigungen steht.also außer allem Zweifel. Eine ganz andere Frage aber ist die, ob das Vorhandensein von Coli ohne weiteres eine gefährliche Verunreinigung, eine Verunreinignng mit Fäkalien beweist. Diese Frage ist zu verneinen! Darin ist den „Ubiquitaristen“ unbedingt Recht zu geben, daß die Colibakterien, und auch die typischen, sehr weit, besonders in den oberflächlichen Schichten des Bodens verbreitet sind, und $\mathrm{da} B$ sie von ihrem eigentlichen Ursprungsort oder ihrer Ablagerungsstelle auf weite Entfernungen verschleppt werden können. Es ist deshalb nicht gesagt, daB in allen Fällen dieselben Zuflüsse, die das Bacterium coli in den Brunnen hineingebracht baben, auch Typhusbazillen ins Wasser bringen können.

Indessen lassen sich doch auch in dieser Frage gewisse quantitative Überlegungen anstellen. Je zahlreicher die Colikeime im Wasser sich finden, und vielleicht auch je typischer sie sich in ihrer quantitativen Säurebildung verhalten, desto nāher - zeitlich und räumlich - wird unter sonst gleichen Umständen ihr Ursprung dem Brunnen sein, und als desto gefährlicher muß die Verunreinigung angesehen werden.

Immer aber wird der Ortsbesichtigung die letzte Entscheidung zufallen; die Coliprobe ist eine wertvolle Ergänzung, aber kein Ersatz der Ortsbesichtigung.

Auch bei der Beurteilung von Quellen kann die Prüfung auf Coli gute Dienste als Indikator einer ungenügenden Filtration leisten, vorausgesetzt, daß es möglich ist, das Quellwasser ohne Beimengung oberflächlicher Zuflũsse zu entnehmen. $O b$ aber mit der ungenügenden Filtration eine Infektionsgefahr verbunden ist, muB auch hier durch genaue Erkundung des Niederschlagsgebietes erwiesen werden. Aber auch hier wird man aus der Zahl und der Art der auftretenden Colibakterien in manchen Fällen Schlüsse auf die GröBe der aus der ungenügenden Filtration drohenden Gefahr ziehen können. 